\title{
Sociological Study of the Influence of Citizen's Traffic Ethics on Driving Violations Case Study Tehran
}

\author{
Zohreh Avaz \\ Tehran Municipal Social Study Office, Tehran, Iran \\ Email:z.avaz@yahoo.com \\ Meeghat Habibian \\ Department of Civil and Environmental Engineering, Amirkabir University of Technology, Tehran, Iran \\ Email: Habibian@aut.ac.ir \\ Sara Moridpour \\ School of Civil, Environmental and Chemical Engineering, RMIT University, Melbourne, 3001, Australia \\ Email: sara.moridpour@rmit.edu.au
}

\begin{abstract}
In this paper, the influence of traffic ethics on driving violations is investigated and modeled from sociological perspective. The driving violation of male and female drivers is separately analyzed in this research. The models are developed based on the survey results of 215 drivers who received driving tickets in Tehran. In this paper, the traffic ethics is considered as a criterion of drivers' obligation to obey traffic rules. To evaluate the drivers' obligation, some social and cultural variables are applied. The social variables which are used in this research include: social anomies, social obligations and social capital and the cultural variables are: influence of media, social-cultural status of people and cultural patterns. The results show that the variables investigated in this paper, as representatives of the human related factors, are able to predict $39 \%$ and $60 \%$ of driving violation in male and female drivers, respectively. According to the results, the social-cultural status has an important influence on citizen's traffic ethnics of male and female drivers. However, considerable difference is observed between the influencing factors on the driving violation of these two categories. For female drivers, the driving violation mainly depends on level of education and media. Meanwhile the influencing variables in male drivers driving violation include: personal obligations, personal confidence, social confidence and belief in inefficiency of traffic rules.
\end{abstract}

Index Terms-driving violation; gender; citizen's traffic ethics

\section{INTRODUCTION}

In recent decades, urbanization had a large growth in the world and especially in developing countries. This phenomenon is due to population growth and massive rural migration to cities. Therefore, the population of

Manuscript received January 1, 2014; revised March 22, 2014. some large cities in the world has more than doubled in the last 25 years [1]. With expansion in the size of cities, the average distance between peoples' work place and homes has increased and this intensifies the need of using vehicles. Meanwhile, increase in the number of vehicles results in traffic congestion on urban transport network. According to the previous studies, human factors are the most important factors in irregularities in traffic and transport accidents [2]-[4].

Nowadays, road traffic accidents cause many deaths throughout the world. According to the European Road Safety Observatory [5], annually 43 thousand people die in traffic accidents in Europe. Approximately, $77 \%$ of all fatalities are males and less than a quarter of them are females. In Iran, there were more than 20 thousand fatalities due to road traffic accidents, in recent years [6]. Also, surveys conducted by Spain's Traffic Department have confirmed that male drivers have received more traffic fines and lost more driving license points than female drivers. The surveys have also shown that female drivers are more compliant with traffic regulations and male drivers are less concerned about road safety issues. In addition, male drivers attach less importance to risky behavior and consider accidents a less serious problem than do female drivers [7], [8].

Disregarding traffic regulations which are important cause of driving violation and traffic accidents in many communities are considered as a function of cultural, social, economic and geographical characteristics of the society. It is noted that driving violation can be classified as intentional and accidental. Intentional driving violations normally occur by ignoring the traffic rules. While, accidental driving violations usually happens when the drivers are not familiar with the driving environment or due to vision problems. In this paper the intentional driving violation is considered. According to 
the statistics, about 23,000 fatal accidents occur in Iran each year (most in rural roads) due to driving violation which results in economic and social irreparable damages. Human factors are identified as the main cause of driving violation in Iran [9]. Human behavior is extracted from the norms and ethical rules in order to establish cohesion in society. Deviation is an inconformity with established norms which are accepted by the majority of people in the society [10]. From the sociological viewpoint, ignoring the traffic rules is one of the important deviations in large cities.

Women's participation in society and their social activities has considerably increased in the last decades. However, most of the previous social deviation studies ignore the influence of gender and only the studies on sex-related crimes (e.g., rape and prostitution) have been focused on women [11]. According to Merton theory, the less participation of women in social deviation activities compared to men is not sufficient to ignore the influence of gender in sociological studies.

Citizens and citizen ethics are important issues in sociology. In summary, the citizen is someone who lives in the city, takes the advantage of the facilities in the city and is responsible to the city and other citizens. Citizen ethics which are the consequence of urban life comprise the responsibilities and obligations of each citizen towards social organizations and other citizens [12]. From the sociological viewpoint, intentional traffic violation is based on citizen's traffic ethics. Citizen's traffic ethics is the obligation to obey traffic rules imposed by traffic authorities [10].

In this paper the influence of citizen's traffic ethics on traffic violation is investigated considering the drivers' gender. Tehran is used as the case study in this paper. The results of this research will assist in providing appropriate solutions to reduce the intentional traffic violations. This paper firstly reviews the literature on driving violation analysis. The methodology which is used in this research will be explained in the following section. It is followed by the detailed explanation of the data used in this study and the method used for data collection. Then, separate models are developed to predict the driving violation of male and female drivers. The final section summarizes the results of the research are provides some recommendations to reduce driving violations and improve citizen's traffic ethics.

\section{LITERATURE REVIEW}

According to Chalabi's theory, ethics comprised two different aspects including social ethics and cultural ethics [13]. Social ethics is defined as responsibility based on moral commands against "others" and consists of indices such as social anomies, social capital and social obligations. These three indices can be used to analyze the driving violation [13]. According to Durkheim and Merton theories, social anomie refers to a situation where, generalized and accepted norms of society are weakened or become ineffective $[11,14]$. The index of social anomies constitutes of the three components including inefficiency of provision, social insecurity and lack of social justice
[15]. Social capital is a combination of existing norms in social systems that promote collaboration of community members and decrease the exchange and communication costs. According to Patnam's theory, the social capital index includes social consciousness, social partnership and social confidence [16]. The index of social obligations is defined as the responsibly of individuals to the society they belong. Social obligations are evaluated at three different levels including public, organic and personal [13]. Cultural aspect of ethics comprises a combination of norms which are based on the culture of a society [13]. Patterning, mass media influence and social-cultural status (examined based on the general knowledge) are considered as indices of cultural aspect of ethics [17].

Patterning occurs as a consequence of sociability. According to Cooley's theory, patterning occurs in either primary or secondary groups. In primary groups the relationship between the group members is informal, face to face and almost stable. Members of a secondary group have formal relationships based on individual interests considering the rules and regulations. Generally, the members of a secondary group have short-term relationship [18].

Mass media is involved in many social activities and provides the individuals with general information they may require in their everyday lives[11],[14], [19]. In modern societies the interactions between the residents of the society are limited. Therefore, the mass media has a key role in culture transition.

In sociology, social-cultural status is defined through the variation among individuals based on their social and cultural status. Social-cultural status depends on the personal evaluation of individuals of social and cultural differences considering general knowledge, occupation, social class and wealth [11], [20], [21]. According to the previous studies, people with higher social-cultural status, has higher sense of conformity to the society rules and therefore social deviation activities (e.g., ignore traffic rules and regulations) is less observed in this groups of people [10].

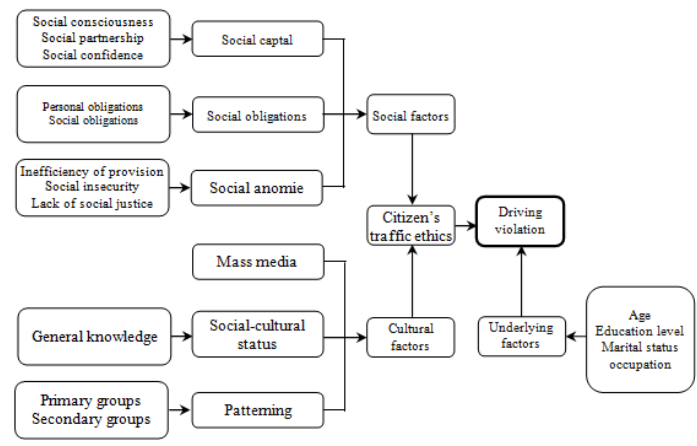

Figure 1. The influencing factors on driving violation.

In addition to moral factors, contextual variables such as age, education level, marital status and occupation are also considered to evaluate the influencing factors on driving violation of male and female drivers. The important variables that may influence the driving violation are summarized and presented in Fig. 1.

\section{METHODOLOGY}


The sample used in this research was selected among all drivers in Tehran city who received driving infringement. Tehran, the capital city of Iran, is the most populated city of the country with an estimated population of about 8.8 million. Tehran stands 17 th by city population, 102nd by the size of its GDP, and 19th by the population of its metropolitan area. Also, it is the largest city in the western Asia with $730 \mathrm{~km}^{2}$ urban area [22]. Passenger car per capita in Iran has been reported to be about 0.025 in $1998,0.113$ in 2008 , and raised up to 0.175 in 2010 . This shows a rapid growth in the car usage in Iranian cities which imposes various problems especially in Tehran which has been subjected to massmigration of people from all around Iran in recent decades [14].

Cluster sampling is used in this paper and Tehran is divided into five different zones including North, South, East, West and Centre. Then, three police stations are randomly selected from each zone to distribute the questionnaires to the drivers who received driving infringement. More than 300 questionnaires are initially distributed in the city, among which 215 are accepted and analyzed. The questionnaires were distributed by police stations to people who had owned car and the driver had a driving violation. The questionnaires were designed to covers three types of information: personal information of drivers, citizen's traffic ethics and previous driving violations. To evaluate the citizen's traffic ethics, a fivepoint Likert scale is used. A Likert scale is a psychometric scale which is commonly involved in questionnaire based research. It is the most widely used approach to scale responses in survey research.

Quantifying the qualitative variables is an important issue in analyzing the data in social studies. The variables usually used in social sciences are mainly different from the variables which are usually used in engineering and science. In social studies scaling methods are used to quantify these concepts. Five-point Likert scale is among the most popular scaling methods. In this method, the variables are categorized into 5 different categories ranging from strongly agree to strongly disagree. Therefore, respondents are allowed to freely answer the questions in the questionnaire (rather than yes or no answers). One number is allocated to each category as a code. These codes are only used to quantify the information. By finding the average of these codes in a questionnaire, it will be possible to quantify the qualitative variables. Table I provides an example of quantifying a qualitative variable using five-point Likert scale.

The drivers' violation is evaluated based on the total driving violations recorded in Tehran in 2009. Accordingly, 12 major driving violations that comprise more than $80 \%$ of the total driving violations in Tehran are selected. These 12 driving violations include: 1) not using seatbelt by passengers, 2) any stop that disturbs the traffic movements, 3) stopping in a no stopping zone, 4) parking where parking is not allowed (no parking sign), 5) speeding, 6) entering the toll zones illegally, 7) using mobile phone while driving, 8) illegal parking without parking permits, 9) stop at the beginning/end of the intersection curves, bridges and tunnels, 10) not paying attention to the police commands, 11) using cars with no roadworthy certificate and 12) driving without having driver's license. In total, 215 questionnaires have been returned which 78 belong to female drivers and 137 of them belong to male drivers.

\section{DRIVING VIOLATION MODELS}

In this paper SPSS software is used to analyze the data and develop the models. In the available dataset the proportion of male and female drivers are $64 \%$ and $36 \%$, respectively. More than $70 \%$ of the total drivers have less than 40 years of age, $38 \%$ are single and $40 \%$ of the drivers have tertiary studies. Around $46 \%$ of the drivers in the dataset have governmental jobs and $40 \%$ of them always use their private cars for their daily trips $(60 \%$ of the drivers in the dataset may use public transport occasionally).

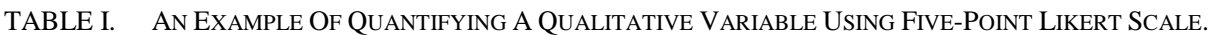

\begin{tabular}{ccccc}
\hline Five-point Likert scale & Strongly Agree & Agree & Neutral & Disagree \\
\hline Traffic rules are sometimes inefficient & 1 & 2 & 3 & 4 \\
\hline
\end{tabular}

\section{A. Female Driving Violation Model}

The summary statistics of female drivers' driving violation is presented in Table II. Tertiary education, lack of driving rules and regulation knowledge, media and patterning from primary groups are the important parameters that can predict $60 \%$ of the female drivers' driving violations. The results of Table I imply that female drivers with higher levels of education are less likely to have driving violations. Furthermore, higher general knowledge prevents female drivers from driving violations. In contrast, unfamiliarity with the driving rules and regulations which may be due to forgetting the driving rules and regulations (or in the case of any changes) have positive correlations with the driving violations [15], [23].

As mentioned earlier, people are influenced by different primary and secondary groups during sociability. According to the results from Table II, women are patterning from their primary groups and media and these two factors have positive correlation with the driving violations in female drivers. This is consistent with the results obtained in the previous studies on drivers' behavior [15],[23].

\section{B. Male Driving Violation Model}

Table III presents the summary statistics of the male drivers' driving behavior. Personal obligations, personal 
confidence, social confidence, belief in inefficiency of the rules, and general knowledge are the influencing factors on driving violations of male drivers. These factors are able to predict around $39 \%$ of the driving violation in male drivers in available dataset. According to the results obtained in this section there is a positive relationship between personal confidences and driving violation in male drivers. This implies that drivers with higher selfconfidence are more probable to have driving violation which is consistent with the previous studies [23]. Also the drivers with higher social confidence are less likely to have driving violations.

TABLE II. SUMmary Statistics OF FEMALE DRIVERS' DrIVING VIOLATIONS AND RELATED VARIABLES.

\begin{tabular}{lcc}
\hline \multicolumn{1}{c}{ Variables } & $\begin{array}{c}\text { Parameter Values } \\
\left(* 10^{4}\right)\end{array}$ & t-statistics \\
\hline Constant & -239.406 & -1.39 \\
\hline $\begin{array}{l}\text { Underlying factors (Tertiary } \\
\text { education) }\end{array}$ & -165.730 & -2.20 \\
\hline $\begin{array}{l}\text { Social capital (Lack of } \\
\text { knowledge) }\end{array}$ & 43.590 & 2.03 \\
\hline $\begin{array}{l}\text { Mass media (Mass media } \\
\text { influence) }\end{array}$ & 53.407 & 2.27 \\
\hline $\begin{array}{l}\text { Social-cultural status } \\
\text { (General knowledge) }\end{array}$ & -90.101 & -5.60 \\
\hline Patterning (Primary groups) & 120.522 & 3.75 \\
\hline Number of observations $=78$ & $\mathrm{R}^{2}=0.60$ & $\mathrm{R}_{\text {adj }}^{2}=0.47$ \\
\hline
\end{tabular}

TABLE III. SUMMARY STATISTICS OF MALE DRIVERS' DRIVING VIOLATIONS AND RELATED VARIABLES

\begin{tabular}{lcc}
\hline \multicolumn{1}{c}{ Variables } & $\begin{array}{c}\text { Parameter Values } \\
\left(* 10^{4}\right)\end{array}$ & t-statistics \\
\hline Constant & 23.651 & 0.41 \\
\hline $\begin{array}{l}\text { Social obligations (Personal } \\
\text { obligations) }\end{array}$ & 29.135 & 2.09 \\
\hline $\begin{array}{l}\text { Social capital (Personal } \\
\text { confidence) }\end{array}$ & 36.986 & 2.82 \\
\hline $\begin{array}{l}\text { Social capital (Social } \\
\text { confidence) }\end{array}$ & -34.475 & -2.23 \\
\hline $\begin{array}{l}\text { Social anomie (Inefficiency of } \\
\text { provision) }\end{array}$ & 30.013 & 2.17 \\
\hline $\begin{array}{l}\text { Social-cultural status (General } \\
\text { knowledge) }\end{array}$ & -35.735 & -4.35 \\
\hline \begin{tabular}{l} 
Number of observations $=215$ \\
\hline
\end{tabular} & $\mathrm{R}^{2}=0.39$ & $\mathrm{R}_{\text {adj }}^{2}=0.29$ \\
\hline
\end{tabular}

According to the results from Table III, there is a positive relationship between the personal obligations and driving violations. Similar results have been revealed in previous studies on personal obligations and prioritizing personal benefits to social benefits. Furthermore, male drivers who believe in inefficiency of provision are more probable to disobey the driving rules. Finally, driving violations and general knowledge have negative correlation in male drivers. Similar to female drivers, the higher level of knowledge may prevent male drivers from driving violations.
The results of this section show that some differences exist between the citizen's traffic ethics in male and female drivers. These differences are summarized in Table IV. According to this table, the factors influencing the driving violation in female drivers are mainly the cultural factors. However, social factors are significant in male drivers' driving violations. Furthermore, socialcultural status is a common factor between male and female drivers that influences driving violations.

TABLE IV. IMPORTANT VARIABLES IN FEMALE AND MALE DRIVERS' DRIVING VIOLATIONS.

\begin{tabular}{cccc}
\hline Gender & $\begin{array}{c}\text { Underlying } \\
\text { factors }\end{array}$ & Social factors & Cultural factors \\
\hline Female & $\begin{array}{c}\text { Level of } \\
\text { education }\end{array}$ & $\begin{array}{c}\text { Unfamiliarity with the } \\
\text { driving rules }\end{array}$ & $\begin{array}{c}\text { Influence of } \\
\text { media } \\
\text { Social-cultural }\end{array}$ \\
\hline Male & --- & $\begin{array}{c}\text { Personal obligations } \\
\text { Personal confidence } \\
\text { Inefficiency of provision } \\
\text { Lack of social confidence }\end{array}$ & $\begin{array}{c}\text { Social-cultural } \\
\text { status }\end{array}$ \\
\hline
\end{tabular}

\section{CONCLUSIONS AND FUTURE RESEARCH DIRECTIONS}

In this paper the influence of human factors as the most important factors on the driving violation of male and female drivers were investigated. The social and cultural factors were analyzed separately.

The results showed that the influencing factors obtained from this research can explain around $40 \%$ of the driving violation in male drivers and around $60 \%$ of the violation in female drivers. Further research to evaluate the influence of other important factors such as social dependency and performance of police on the driving violation will be useful. According to the results from this research, it is inappropriate to provide one solution to reduce the driving violation in male and female drivers. Therefore, separate solutions are suggested for male and female drivers to reduce their driving violations. These solutions are as follows:

- Teaching the appropriate patterns in media: women are the largest population using the mass media. Therefore, teaching the appropriate pattern through the media will be useful for this group. Using instructive animation, advertisements and short sentences will be useful for female drivers.

- Enhancing the social consciousness: unfamiliarity with the driving rules and regulations was one of the important factors in driving violation of female drivers. Therefore, enhancing their social consciousness in the field of traffic will be useful. It will be appropriate to have some workshops in schools, health centers and community centers to enhance the social consciousness of female drivers.

- Demonstrating the efficiency of provision: believe in inefficiency of provision is one of the influencing factors in driving violation of male drivers. Therefore, providing some brochures and booklets to explain the practical reasons behind the traffic rules will be important for male drivers. Furthermore, forcing male drivers to attend workshops and classes 
which explain the importance of traffic rules will be useful. For instance, male drivers need to attend those classes and workshops to be able to extend their expired driver's license.

- Improving the social confidence: lack of social confidence was an important factor in driving violation of male drivers. Providing facilities/bonus for the drives without driving violation will improve their social confidence and provides the opportunity for the male drivers to trust traffic organizations. This will also assist in reducing the driving violation.

\section{REFERENCES}

[1] A. A. Pirhadi, Citizenship Rights, Sorush Publisher, Tehran, Iran, 2007.

[2] M. Gunilla and L. A. Bjorklund, "Driver behavior in intersections: Formal and informal traffic rules," Transportation Research Part F Traffic Psychology and Behaviour, vol. 8, no. 3, pp. 239-253, 2005.

[3] S. Laapottia, E. Keskinena, and S. Rajalin, "Comparison of young male and female drivers' attitude and self-reported traffic behaviour in Finland in 1978 and 2001," Journal of Safety Research, vol. 34, pp. 579-587, 2003.

[4] S. Mackenzie, J. Bannister, J. Flint, S. Parr, A. Millie, and J. Fleetwood, "The drivers of perceptions of anti-social behaviour," Home Office Research Report (34), 2010.

[5] M. R. Rasouli, M. Nouri, M. R. Zarei, S. Saadat, and V. RahimiMovaghar, "Comparison of road traffic fatalities and injuries in Iran with other countries," Chinese Journal of Traumatology, vol. 11, no. 3, pp. 131-134, 2008.

[6] European Road Safety Observatory. (2007). Traffic safety basic facts 2007. Main figures. [Online]. Available: http://www.erso.eu

[7] Direccion General de Tráfico (2008). Barometro de opinion sobre la seguridad vial. Oleada: Diciembre, 2008.

[8] Direccion General de Tráfico: a tu lado vamos todos. [Online]. Available: http://www.dgt.es/was6/portal/contenidos/documentos/seguridad_ vial/estudios_informes/Informe_ejecutivo_dic_08.pdf

[9] Direccion General de Traffico. (2009). Barometro de opinion sobre seguridad vial. [Online]. Available: http://www.dgt.es/was6/portal/contenidos/documentos/seguridad_ vial/estudios_informes/342_DGT_Informe.pdf

[10] Z. Avaz and M. Habibian, "Influence of citizen's traffic ethics on driving violation," in Proc. $10^{\text {th }}$ International Conference on Traffic and Transport Engineering, Tehran, Iran, 2011.

[11] A. Giddens, Sociology, Cambridge, Polity Press, 1989.

[12] N. Fakohi, Urban Anthropology, Ney Publisher, Tehran, Iran, 2004.

[13] M. Chalabi, Social Analysis on act Region, Ney Publisher, Tehran, Iran, 2007.

[14] K. A. Avrenli, R. Benekohal, and H. Ramezani, "Investigating the risky driving behavior of vehicles with short time gaps in singlelane work zones," in Proc. $90^{\text {th }}$ Transportation Research Board Annual Meeting, Washington, D.C., CD-ROM, 2011.

[15] A. Rezaee, "The study of driver's violations," Traffic Congers National, Esfahan, Iran, 2006.

[16] J. S. Coleman, Foundations of Social Theory, Cambridge, Belknap press of Harvard University Press, 1990.

[17] M. Shiani, "Citizen's ethics and the problems in Iran," Ph.D. thesis, Allameh-Tabatabaie University, Iran, 2002.

[18] L. A. Coser, Masters of Sociological Thought, 1986.

[19] S. Zhou, K. Li, J. Sun, and J. Qiao, "Development of macroscopic quality management procedure for intersection safety improvement in China," in Proc. 90 th Transportation Research Board Annual Meeting, Washington, D.C., CD-ROM, 2011.

[20] S. Sontikul, K. Kanitpong, and P. Jiwattanakulpaisarn, "Driver typology and speeding behavior in speed enforcement zone," in Proc. 90 ${ }^{\text {th }}$ Transportation Research Board Annual Meeting, Washington, D.C., CD-ROM, 2011.

[21] W. Zhang, K. Gkritza, N. Keren, and S. Nambisan, "Evaluation of Iowa's driver improvement program," in Proc. $90^{\text {th }}$ Transportation Research Board Annual Meeting, Washington, D.C., CD-ROM, 2011.

[22] WIKIPEDIA. [Online]. Available: http://www.wikipedia.org/

[23] B. Gonzalez-Iglesias, J. M. Gomez-Fraguela, and M. A. LuengoMartin, "Driving anger and traffic violations: Gender differences," Transportation Research Part F: Traffic Psychology and Behaviour, vol. 15, no. 4, pp. 404-412, 2012. 